\title{
RESEARCH ON THE SPATIAL VARIABILITY OF SOIL MOISTURE BASED ON GIS
}

\author{
Changli Zhang ${ }^{1}$, Shuqiang Liu ${ }^{2, *}$, Junlong Fang ${ }^{1}$, Kezhu Tan ${ }^{3}$ \\ ${ }^{I}$ Engineering College, Northeast Agricultural University, Harbin, Heilongjiang, China, \\ 150030 \\ ${ }^{2}$ Heilongjiang Institute of Technology, Harbin, Heilongjiang, China, 150050 \\ ${ }^{3}$ Chengdong College, Northeast Agricultural University, Harbin, Heilongjiang, China, \\ 150030 \\ * Corresponding author, Address: Academic Administration, Heilongjiang Institute of \\ Technology, 999 Hongqi Road, Harbin, Heilongjiang, 150050, P. R. China, Tel: +86-0451- \\ 88028684, Fax: +86-13946117239, Email: shuqiangliu@hotmail.com
}

Abstract: $\quad$ With the help of GPS and measuring instrument of soil moisture, soil moisture was measured and analyzed. As using Geo-statistics to the study of spatial variability of soil moisture and use ArcGIS 9.0, get the spatial distribution map of soil water property with Kriging interpolation. The research result showed that all soil spatial characters are normal distribution and the spatial distribution of soil water property accord with the fact. Geo-statistics Methods is the most appropriate methods in all of Mathematical Methods for Geostatistics. The spatial distribution map of soil water property what got with Kriging interpolation can make the spatial distribution of the entire plot, more accurate and reliable. Getting a veracious spatial distribution map of soil water speciality was very important and useful for adjusting precision fertilization and precision irrigation in time. It also offered the theoretical foundation of the connection studying between soil water speciality and enhancing the yield.

Keywords: Geographical information system, spatial interpolation, Geo-statistics, spatial variability

\section{INTRODUCTION}

Soil was inhomogeneous and continuous nature. Actual instance in the field indicated, in the synchronization, soil speciality also had obvious difference on the different spacial situation; this property was named the 
spatial variability of soil moisture (Meng et al., 1992). The most intuitionistic mode of the spatial variability of soil moisture was the spatial distribution map of soil water. Therefore, the all-important work and base of Precision Agriculture is producing the spatial distribution map of soil moisture reliably. This study researched the spatial variability of soil moisture based on Geo-statistics, and applied Kriging interpolation of ArcGIS 9.0 to produce the spatial distribution map of soil moisture, it could offer the scientific evidence for farm management system.

\section{BASIC THEORY AND METHOD OF THE SPATIAL VARIABILITY}

\subsection{Regionalized variables theory}

When a variable assumed spacial distribution, it was regionalized variable (Jun et al., 2000; Zhang et al., 1995). The variables reflected distributing character of some spatial property. Regionalized variables had two important characters: the first one was that regionalized variables $\mathrm{Z}(\mathrm{X})$ was a random function, its character were local, stochastic, exceptional; the second one was that regionalized variables had ecumenical and average structure quality, the variables $\mathrm{Z}(\mathrm{X})$ and $\mathrm{Z}(\mathrm{X}+\mathrm{h})$ had correlation in some extent at point $\mathrm{X}$ and point $X+h$ that its acentric spatial distance was $h$. At some significance, this was structural character of regionalized variables. Soil moisture and other farmland information were all regionalized variables, therefore it can use regionalized variables theory to study their spatial variable laws.

\subsection{Semi-varionram function}

Farmland information was fully random variables, analyzed by traditional statistics. The most research only considered mean value and dispersion coefficient of all the observable value, and not considered the difference of the observable point. But actually, most of farmland information was a spatial-temporal continuous variants, not only had randomicity but also had structure. Therefore, it could use semi-varionram function of studying spatial variance of regionalized variables in Geo-statistics to describe spatial variability of farmland information.

Semi-varionram function was a function which described the spatial variability structure of Soil Moisture, scaling spatial correlative extent of known points, calculated by this formula: 


$$
\gamma(h)=\frac{1}{2 n} \sum_{i=1}^{n}\left(z\left(x_{i}\right)-z\left(x_{i}+h\right)\right)^{2} a
$$

In which: $\mathrm{h}$ was the distance of known points, frequently be lag; $\mathrm{n}$ was the number of conjugated swatch points disjoined by $\mathrm{h}$; $\mathrm{z}$ was attribute value. Semi-varionram was augmenting along with $\mathrm{h}$ augmenting.

Semi-varionram function was generally expressed by variance curve, it was a function map with $\mathrm{r}(\mathrm{h})$ to $\mathrm{h}$. Fig. 1 is a representative sketch map of Sphere Model semi-varionram function. $\mathrm{C}_{0}$ was fundus variance, expressed spatial variance by semi-varionram, it was generally metrical error by observation variance. The a was mutative distance, it expressed that there was distance upper limit in the sampling data. When $\mathrm{h} \leq \mathrm{a}$, the observation value between random two points had relativity that which was augmenting along with $h$ falling; When $h>a$, there were no relativity. $C_{0}+C$ was $r(h)$, it reflected spatial variance intensity of some observational variable in the research region. The eigenvalue of function expressed variable character of observational variable.

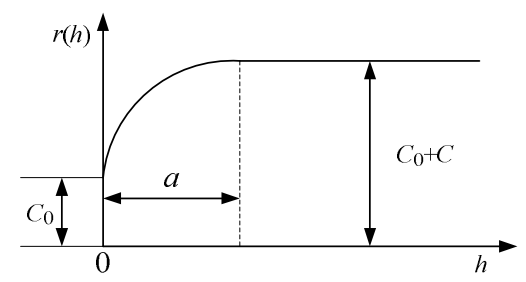

Fig. 1. Semi-varionram of spherical fitted model

\subsection{Theoretic model of semi-varionram function}

When describing quantificationally variable character of all the research region, it need produce semi-varionram map. It need seek theoretic model of semi-varionram for produce semi-varionram map (Zhang et al., 1995; Feng et al., 2000; Huang et al., 2002; Li et al., 1998), this model attached straightway oneself to Kriging calculation. On account of Kriging formula positive quality, actually there were only some theoretic model of semi-varionram function, generally, Spherical Model, Index Model, Gauss Model, Power Model, Sine Model.

1) Spherical Model

$$
\begin{array}{cc}
\gamma(h)=\left\{\begin{array}{cc}
0 & h=0 \\
c_{0}+c_{1}\left\{\frac{3}{2} \frac{|h|}{a}-\frac{1}{2}\left(\frac{|h|}{a}\right)^{3}\right\} & 0<|h| \leq a \\
c_{0}+c_{1} & |h|>a
\end{array}\right. \\
h=a, r(h)=C_{0}+C .
\end{array}
$$


2) Index Model

$$
\gamma(h)=\left\{\begin{array}{cl}
0 & h=0 \\
c_{0}+c_{1}(I-\exp (-3|h| / s)) & h \neq 0
\end{array}\right.
$$

3) Gauss Model

$$
\gamma(h)=\left\{\begin{array}{cl}
0 & h=0 \\
c_{0}+c_{1}\left(I-\exp \left(-3\left(\frac{|h|}{a}\right)^{2}\right)\right) & h \neq 0
\end{array}\right.
$$

\subsection{Used Kriging interpolation to produce the distributing map of soil moisture}

With semi-varionram function, it can reflect spatial variable rule of region variable exactly. We can produce the distributing map of soil moisture by Kriging interpolation after selecting theoretic model of semi-varionram function. It was a method that which made use of the structure of original data and semi-varionram function, it valuated best and truly localizable variable of unknown points ( $\mathrm{Lu}$ et al., 1985). It considered distance and the relation of known swatch points and unknown points by the structure of original data and semi-varionram function. Kriging interpolation got the value of unknown points by endowing known points with weight, it expressed:

$$
Z\left(x_{0}\right)=\sum_{i=1}^{n} \lambda_{i} Z\left(x_{i}\right)
$$

In which: $\mathrm{Z}\left(\mathrm{x}_{0}\right)$ was the value of unknown points, $\mathrm{Z}\left(\mathrm{x}_{\mathrm{i}}\right)$ was known swatch points around unknown points, $\lambda_{i}$ was the power that point $i$ to unknown points. For satisfying non-Biased and optimality, passed establishing Kriging formula to ascertain weight coefficient (Li et al., 2006):

$$
\left\{\begin{array}{l}
\sum_{j=1}^{n} \lambda_{j} \gamma\left(x_{i}, x_{j}\right)+\mu=\gamma\left(x_{i}, X\right) \\
\sum_{i=1}^{n} \lambda_{i}=1
\end{array}\right.
$$

In which: $\gamma\left(x_{i}, x_{j}\right)$ was covariance function in sampling points, $\gamma\left(x_{i}, X\right)$ was covariance function between sampling points and interpolation points, $\mu$ was Lagrange multiplier. 


\section{DESIGN OF THE EXPERIMENT}

Experiment farmland was a soybean field of Heilongjiang Daxijiang farm, its area was about $9.8 \mathrm{hm} 2$. June 27, 2006, soil moisture was measured with the help of GPS and measuring instrument of soil moisture, grid was setting by $15 \mathrm{~m} \square 15 \mathrm{~m}$, about 250 points, sampling deepness was $10 \mathrm{~cm}$.

Sampling mode of soil moisture was point sampling (Joseph K. Berry et al., 1999; Wollenhaupt N.C. et al., 1997; Hao et al., 2002), inerratic grid sampling disjoin the farmland to equal area grid. It was simple and exercisable, was the most effective one of sampling method. This research considered sampling convenience and actual condition, compartmentalized grid along ridge in a field generally.

\section{ANALYZED THE DATA}

\subsection{Calculated the statistical eigenvalue of soil moisture}

Based on classical statistics, we calculated statistical eigenvalue of the data of soil moisture in the experiment farmland; experimental results were shown in Table 1. Variance coefficient were respectively 119.2, 117.3, 127.6, all belong to strong variability.

Table 1. Statistical description of soil moisture

\begin{tabular}{lllllll}
\hline Date & $\begin{array}{l}\text { Minimum } \\
\text { value }\end{array}$ & $\begin{array}{l}\text { Maximal } \\
\text { value }\end{array}$ & $\begin{array}{l}\text { Average } \\
\text { value }\end{array}$ & $\begin{array}{l}\text { Standard } \\
\text { value }\end{array}$ & Variance & $\begin{array}{l}\text { Variance } \\
\text { coefficient }\end{array}$ \\
\hline June 27, 2006 & 0.09 & 0.357 & 0.224 & 0.267 & 0.071 & $119.2 \%$ \\
July 17, 2006 & 0.086 & 0.33 & 0.208 & 0.244 & 0.06 & $117.3 \%$ \\
August 8, 2006 & 0.099 & 0.45 & 0.275 & 0.351 & 0.123 & $127.6 \%$ \\
\hline
\end{tabular}

\subsection{Testing normal distribution of soil moisture data}

Testing for normal distribution of soil moisture data was the precondition of using Kriging interpolation of Geo-statistics to analyze soil moisture data. If sampling data submitted to normal distribution, its sampling points should be linear. In ArcGIS, we tested normal distribution to soil moisture data by normal QQ plot (Fig. 2), the result indicated that most points accord with normal distribution. Several points left the beeline overmuch, after testing, it was eligible. 


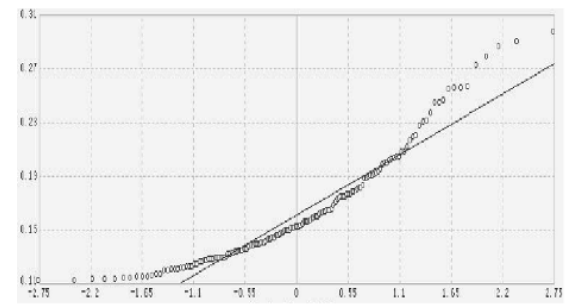

June 27,2006

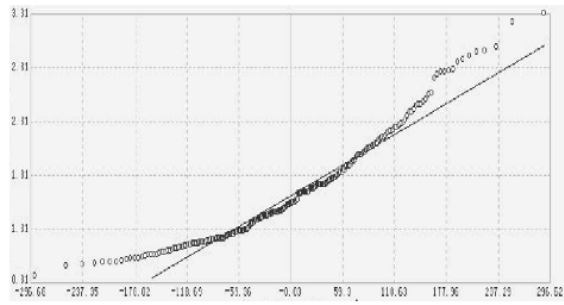

July 17,2006

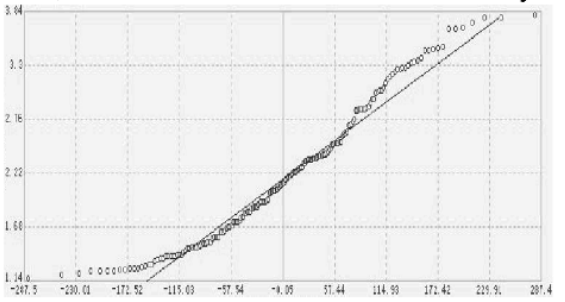

August 8, 2006

Fig. 2. Normal QQ plots of soil moisture properties

\subsection{Spatial interpolation analyzed soil speciality}

For describing true and intuitionistic spatial distribution of soil moisture, the research used Spatial Analyst module in ArcGIS 9.0, applied the Kriging to get the distributing map of soil moisture. Experimental results were shown in Fig. 3, Fig. 4, Fig. 5.

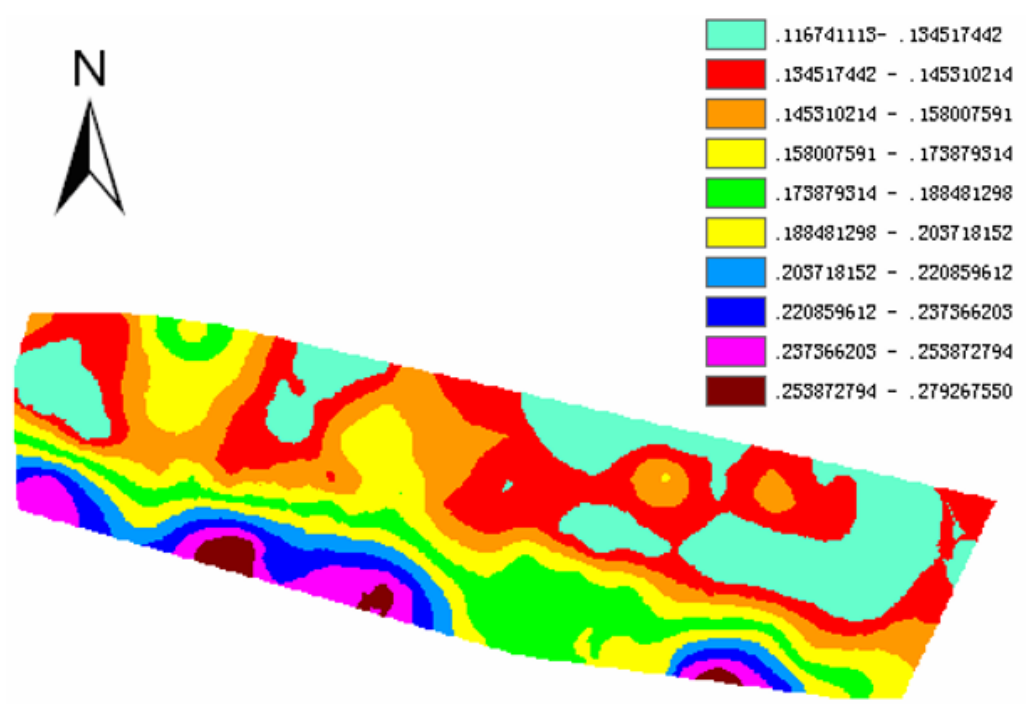

Fig. 3. The spatial distribution map of soil moisture 


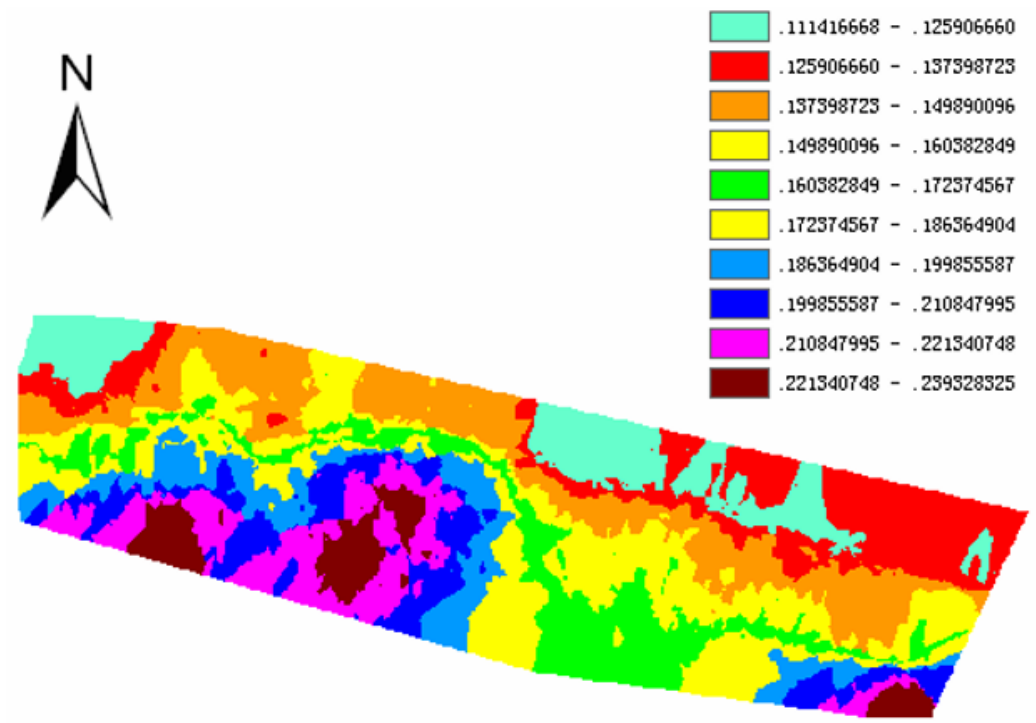

Fig. 4. The spatial distribution map of soil moisture

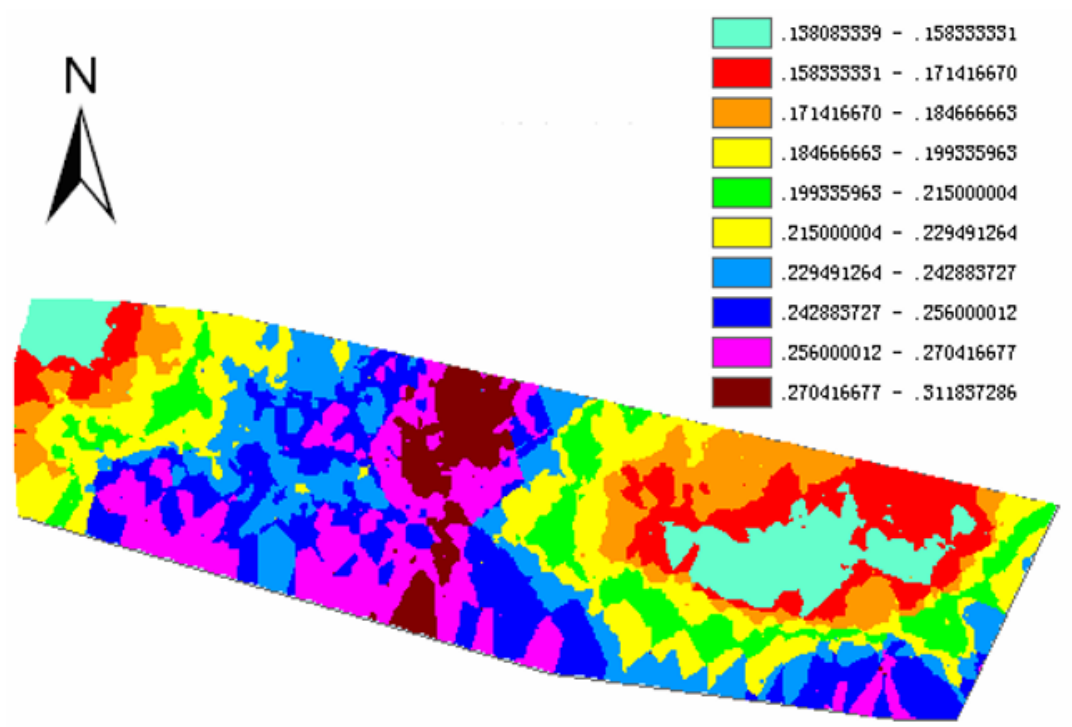

Fig. 5. The spatial distribution map of soil moisture

We saw the spatial distribution of soil moisture. In this farmland, there were low of the north and high of the south. It was consistent with the fact. 


\section{CONCLUSIONS}

1) All of the soil spatial property is normal distribution and the spatial distribution of soil water property accord with the actual.

2) Kriging only considered the relativity of the data, it didn't only consider the randomicity of the soil property, but also considered the structure of the soil property. The spatial distribution map of soil moisture by Kriging can analyze the spatial distributing status of all the cropland. Getting a veracious spatial distribution map of soil water property is very important and useful for adjusting precision fertilization and precision irrigation in time. It also offered the theoretical foundation of the connection studying between soil water property and enhancing the yield.

3) When using spatial interpolation methods, it should choose the best method to get the most perfect effect of the spatial interpolation, the precondition is comparing the experimentations with the different actual instance of the experimental cropland and analyzing the actual metrical data of the sampling points adequately. The most importance was improving on interpolation methods, putting forward a new better scientific interpolation based on existing foundation.

Although there are intensive agriculture produces in the northern of our country, the water resources of our country are scarce very much. Heilongiiang is a place which is short of water source seriously. Getting a veracious spatial distribution map of soil water property is very important and useful for adjusting precision fertilization and precision irrigation in time. It also offers the theoretical foundation of the connection studying between soil water property and enhancing the yield.

\section{ACKNOWLEDGEMENTS}

This study has been funded by innovating program of NEAU. Sincerely thanks are also due to Heilongjiang Daxijiang farm for providing the experiment farmland for this study.

\section{REFERENCES}

Feng X.Z., Bo Y.C., Shi Z.T. 2000. Snow Depth in North Xinjiang Region Estimated by Kriging Interpolation. Journal of Glaciolgy and Geocryology. 22(4):358-361.

Hao P.F., Liu G., Jiang W.K. 2002. Approaches to processing soil fertility spatial distribution information for precision agriculture. Journal of Agricultural University of Hebei. 25: 277-278. 
Hua M., Wang J. 1992. Soil Physics. BeiJing: BeiJing agriculture publishing company.

Huang Sh.W., Jin J.Y., Yang L.P. 2002. Spatial Variability of Soil Nutrients in Grain Crop Region of Yutian County. Chinese Journal of Soil Science. 33(3):188-193.

Joseph K. Berry. The Precision Farming Primer. BASIS, Inc.1999.

Li J., You S.C., Huang J.F. 2006. Spatial interpolation method and spatial distribution characteristics of monthly mean temperature in China during 1961-2000. Ecology and Environment. 15(1):109-114.

Li J.M., Li Sh.X. 1998. Spatial variance of several nutrition element in the soil. Agricultural Research in the Arid Areas. 16(2):58-64.

Lu W.D., Zhu Y.L., Sha J. 1985. The elementary study on spatial variability of soil speciality. Journal of North China Institute of Water Conservancy and Hydroelectric Power. (9): $10-21$.

Wang J., Fu B.J., Qiu Y. 2000. Spatiotemporal Variability of Soil Moisture in Small Catchment on Loess Plateau-Semivariograms. ACTA GEOGRAPHICA SINICA. 55(4):428-438.

Wollenhaupt N.C., Mulia D.J., Gotway Crowford C.A. 1997. Soil Sampling and Interpolation Techniques for Mapping Spatial Variability of Soil Properties. The Site-Specific Management for Agricultural Systems. ASA-CSSA-SSSA, 777 S. Segoe Rd., Madison, WI53711, USA. 19-53.

Zhang X.F., Van Eijkeren J.C.H., Heemink A.W. 1995. On the Weighted Least-Squares Method for Fitting a Semivariogram Model. Computers \&Geosciences. 21(4):605-608. 